\title{
Auricular Acupuncture for Suicidal Ideation in Methadone Patients
}

\author{
Saeed Nateghi ${ }^{1,{ }^{*}}$ and Hosein Effatpanah ${ }^{2}$ \\ ${ }^{1}$ School of Medicine, Ziaeian Hospital, International Campus, Tehran University of Medical Sciences, Tehran, Iran \\ ${ }^{2}$ Department of Public Health, Asadabad School of Medical Sciences, Asadabad, Iran \\ "Corresponding author: School of Medicine, Ziaeian Hospital, Tehran University of Medical Sciences, District 17, Abouzar St, P.O. Box: 1366736511, Tehran, Iran. Tel: \\ +98-2155176814, Email: mafsaneh45@gmail.com
}

Received 2019 September 16; Revised 2019 November 11; Accepted 2019 November 30.

Keywords: Drug, Methadone, Treatment

\section{Dear Editor,}

Illicit drug use remains a health concern in Iran which is accompanied with a number of serious problems such as suicide and mortality (1-3). In addition to methadone, a number of psychological interventions have been introduced to treat this problem which are not necessarily effective for every patient (4-9).

In a recent published article in your journal, "evaluation of the effectiveness of auricular acupuncture in suicidal ideation and cortisol level in dysthymic patients with comorbid opiate use disorder enrolled in methadone maintenance treatment: a randomized double-blind, sham controlled trial", authors have suggested a new intervention to treat suicidal ideation in methadone therapy in Iran (10). Overall, 24 methadone patients with the diagnosis of depression received either auricular acupuncture (AA) or sham acupuncture during four weeks. Interestingly, participants in the treatment group showed significantly better results than the control group in term of reduced suicidal ideation (10).

In this letter to editor, we appreciate the study as a valuable and influential research because it suggests a new intervention to treat suicidal ideation in Iran. The message of the study is important for Iranian health policy makers and clinicians; suicidal ideation is one of the leading causes of death in methadone therapy and with using new effective interventions such as AA, we can reduce the mortality rate in this group. Therefore, reduced depression and as a result, reduced suicidal ideation are very likely to contribute to improving methadone treatment outcomes. Although more large-scale randomized controlled trials are needed to investigate the effectiveness of AA as a reliable treatment, the study is still important and deserves replication. Moreover, the authors cannot limit themselves to AA. Other treatments such as pharmacological treatments combined with AA should be considered in future for suicidal ideation in methadone patients. Furthermore, the literature related to AA is emerging in Iran and further studies are need. Such studies need to have a focus on large trial and should not limit themselves to quasi-experimental studies with limited sample sizes.

\section{Footnotes}

Authors' Contribution: Saeed Nateghi and Hosein Effatpanah wrote the letter to editor. Saeed Nateghi and Hosein Effatpanah contributed to editing, revising and approving the final draft of the letter.

Conflict of Interests: There is no conflict of interest.

Funding/Support: No funding or support has been received.

\section{References}

1. Rafiey H, Ghaderi S, Morovat B, Noori R, Effatpanah M, Mahjoub A, et al. Amphetamine type stimulants use in the adult population of Tehran: Implications for long term rehabilitation. Iran Rehabil J. 2017;15(4):303-8. doi: 10.29252/nrip.irj.15.4.303.

2. Dana S, Effatpanah M, Mahjoub A. The new epidemic problem of psychoactive drugs at drug treatment centers of iran: Implications for education, prevention and treatment. Iran J Psychiatry Behav Sci. 2018;12(2). e63555. doi:10.5812/ijpbs.63555.

3. Massah O, Effatpanah M, Moradi A, Salehi M, Farhoudian A, Karami Z. Barriers to hepatitis $C$ treatment among women in methadone treatment: A study from Iran, the most populous Persian Gulf country. Addict Health. 2017;9(4):229-36. [PubMed: 30574286]. [PubMed Central: PMC6294482].

4. Effatpanah M, Moradi A. Methamphetamine dependence and technology-based interventions in Iran. Iran J Psychiatry Behav Sci. 2018;12(2). e62935. doi: 10.5812/ijpbs.62935.

5. Salimi S, Effatpanah M, Mahjoub A. Motivational interviewing can facilitate entry to matrix treatment for methamphetamine dependence. Iran J Psychiatry Behav Sci. 2018;12(2). e63560. doi: 10.5812/ijpbs.63560. 
6. Shakiba K, Effatpanah M, Moradi A. Cognitive-behavioral therapy for methamphetamine dependence among methadonemaintained patients. Iran J Psychiatry Behav Sci. 2018;12(2). e63615. doi: 10.5812/ijpbs.63615.

7. Massah O, Effatpanah M, Shishehgar S. Matrix model for methamphetamine dependence among Iranian female methadone patients: The first report from the most populated Persian Gulf country. Iran Rehabil J. 2017;15(3):193-8. doi:10.29252/nrip.irj.15.3.193.

8. Shariatirad S, Mahjoub A, Haqiqi A, Rezaei Hemami M, Tofighi B, Ekhtiari H, et al. Buprenorphine added on brief cognitive behavioral therapy for treatment of methamphetamine use disorder. Iran J Psy- chiatry Behav Sci. 2018;12(2). doi: 10.5812/ijpbs.11529.

9. Sami S, Effatpanah M, Moradi A, Massah O. Matrix model as an intensive rehabilitation in three methadone services in Iran. Iran Rehabil J 2017;15(3):293-8. doi: 10.29252/nrip.irj.15.3.293.

10. Pirnia B, Mohammadi AR, Zahiroddin A, Mohammadzadeh Bazargan N, Malekanmehr P, Pirnia K. Evaluation of the effectiveness of auricular acupuncture in suicidal ideation and cortisol level in dysthymic patients with comorbid opiate use disorders enrolled in methadone maintenance treatment: A randomized, double-blind, sham-controlled trial. Iran JPsychiatry Behav Sci.2019;13(2). e12498. doi 10.5812/ijpbs.12498. 